\title{
Performance Assessment and Monitoring of Water Infrastructure: An Empirical Case Study of Benchmarking in Uganda
}

\author{
By: Dr. Silver Mugisha ${ }^{1}$
}

April, 2006

\begin{abstract}
Performance monitoring and benchmarking are increasingly becoming vital performance drivers especially in utilities where strong tariff incentive applications are not readily applicable. In this paper, I present performance improvement initiatives in National Water and Sewerage Corporation (NWSC) - Uganda, incorporating practical benchmarking and performance monitoring approaches. I also outline a detailed empirical study of the influence of commercial/customer orientation on technical efficiency using Stochastic Frontier Analysis (SFA) benchmarking techniques. I find that after a long spell of heavy engineering orientation in a water utility, a shift to significant commercial/customer orientation is positively associated with reduction in technical inefficiencies.
\end{abstract}

KEY WORDS: Benchmarking, Monitoring, Commercial Orientation, Customer Orientation, Stochastic Frontier Analysis (SFA).

\section{Introduction}

Many water utilities in low income countries, in an effort to revamp their performances often begin with heavy infrastructural investment projects. Experience has shown that focussing on this engineering approach alone does not deliver the required efficiency gains. There is need to have a mix of orientations depending on where managerial weaknesses are most prevalent in the utility. The other dimension that needs significant attention in water infrastructure management is benchmarking and performance monitoring. Benchmarking is increasingly becoming a strong performance driver especially in utilities where strong tariff incentive applications are not readily applicable. It is a good mechanism for keeping the

\footnotetext{
${ }^{1}$ Dr. Silver Mugisha is the Manager in charge of Research, Monitoring and Evaluation and also Head of External Services at National Water and Sewerage Corporation, Uganda. He is a Civil Engineer who specializes in Institutional Development and Performance Management. He has been involved as a Team Leader in a number of NWSC external services assignments in Dar es Salaam, Tanzania; Lusaka and Kitwe, Zambia, Nzoia Cluster, Kenya. Mugisha contact address is Silver.Mugisha@nwsc.co.ug and his phone-contacts are +256-41-315109(O) and +256-77-2590178 (Cell)
} 
regulator-regulated interface active in a meaningful manner. If well structured, it puts pressure on the operating utility to deliver what was promised. At the same time, it gives the regulator a proactive framework to operationalise its mandate to foster improved performance in the water industry. In this paper, I present case of National Water and Sewerage Corporation (NWSC) - Uganda, highlighting a brief account of performance improvement approaches, achievements and lessons learned. I also outline a detailed empirical evidence highlighting how balancing engineering orientation with commercial/customer care orientation significantly enhance infrastructure performance.

\section{Overview of the Urban Water Sector Performance in Uganda}

In Uganda, the water and sanitation sector falls under the Ministry of Water, Lands and Environment (MWLE). Since 1998, the MWLE has been undergoing a number of water sector reform initiatives to improve performance. One of the major arms of the Ministry that has undergone significant reforms is National Water and Sewerage Corporation (NWSC). The NWSC is a public corporation wholly owned by the government of Uganda, having been established in 1972 by decree No. 34. The corporation's legal position was strengthened by NWSC Statute No. 7 of 1995, which was later enacted into NWSC Act of 2000. Under the new legal framework, the powers and structure of NWSC were revised to enable the corporation operate on a commercial and financially viable basis. Accordingly, the corporation is currently mandated to manage water and sewerage services in 19 Urban Areas under its jurisdiction. Uganda's urban population is about 4 million people and out of this NWSC towns constitute about 2.5 million people (62 percent). The service coverage in the NWSC towns, as at June, 2005 was 68 percent. This is a clear indication that much more needs to be done to increase accessibility the water - the basic need. It must be noted that Uganda's urban population is about 15 percent of the total population that stands at about 25 million people.

The performance situation in NWSC as at 1998 was extremely appalling! At that time, the World Bank noted in their report that: "Over the last 10 years, the Government of Uganda in partnership with the World Bank and other Donors have made significant investments (over US \$ 100 million) in the Urban Water and Sewerage sector. These investments have contributed immensely in rehabilitating the existing infrastructure under the NWSC management. Unfortunately, these investments have not been matched with the necessary efficient commercial and financial management capacity that can ensure the delivery of 
sustainable services in the medium to long-term". This conclusion was after a thorough situation analysis in which it was found out that the corporation had sound infrastructure, abundant water resources and enabling legislative framework. However, the corporation had a number of problems. There was a large and inefficient labour force with conflicting and overlapping roles, high Unaccounted for Water (more than 50 percent), poor customer care, low collection efficiency (about 71 percent), huge debts aging about 14 months and corrupt field staff. The corporation had to contend with a number of threats, which included debt servicing obligations and a Value Added Tax (VAT) law that compelled it to pay taxes on any bills raised. The only consolation was that Government was willing to give support to proactive managers and the economy was relatively stable. But, in a nutshell, there was urgent need to improve operational and financial performance of the corporation.

\section{Performance Improvement Strategies and Achievements}

In order to address the declining performance trends in NWSC a new Board of Directors was appointed in 1998, which in turn appointed a new Chief Executive - Dr. William Tsimwa Muhairwe. Under the stewardship of Dr. Muhairwe ${ }^{2}$, management come up with 100-Days programme, a high-impact programme focused on reversing the operational and financial inefficiencies. This was followed by Service and Revenue Enhancement Programme, aimed at restoring customer confidence and hence service delivery. Thereafter, the corporation designed and implemented Area and Service Performance Contracts focusing on break-even of Areas by empowering managers and giving them autonomy to take important decisions. Next, a Stretch-Out programme was then implemented. The programme focused on improvement of operating margins by reducing bureaucracy, increasing speed, simplicity, worker involvement and instilling self confidence. However, the Stretch-Out put emphasis on teamwork and did not adequately cater for individual performance accountability. Consequently, the corporation was compelled to design and implement a OneMinute Management Programme to cater for this omission. Currently, NWSC is implementing Internally Delegated Area Management Contracts (IDAMCs) aimed at giving more autonomy to Areas, clear role definition, better incentive plans and apportioning more operating risks to Partners. Details of the performance improvement programmes that have been implemented in NWSC since 1998 can be found on www.nwsc.co.ug.

\footnotetext{
${ }^{2}$ Dr. Muhairwe has since been a Chief Executive of NWSC up to the current date.
} 
The change management programmes, which have been implemented in NWSC since 1998 up to 2005 have resulted into a number of achievements. Notably, the service coverage has increased from 48 percent to 68 percent. The water network coverage has increased by 45 percent $(850 \mathrm{Km}$ of water mains extensions; $710 \mathrm{Km}$ from internally generated funds and $140 \mathrm{Km}$ from external funding). In addition, new connections have increased from 3,317 No to 22,218 No per year. As a result, total connections have increased from 50,826 to 125,000. Unaccounted for water has reduced from 51 percent to 31 percent (Kampala is 35 percent while other Areas: 16 percent). Metering Efficiency has increased from 65 percent to 98 percent, while connection efficiency (proportion of active connections to total connections) has improved from 63 percent to 91 percent. On the financial side, annual turnover has improved from about US\$11M to US\$30M. Because of this performance, operating Profit after Depreciation has improved from loss of US\$ $0.4 \mathrm{M}$ to a surplus of US\$2.2M.

According to Muhairwe (2006), 'NWSC experience has shown that that a hardworking and committed Board of Directors with a good mix of skills is necessary if an organisation is to make meaningful progress. In addition, there is need for strong, dynamic utility management and staff team motivated by clear vision, mission and objectives. Furthermore, it is necessary to secure government and donor commitment to support key initiatives like the debt freeze and payment of government debts. It must also be noted that more autonomy through decentralization, strong monitoring and evaluation (M\&E), comparative competition and financial incentive applications are important factors. Other facets include the need to incorporate metrics and process benchmarking with utilities in comparable environments. Last but not least, organizational behaviour change towards strong customer and commercial orientation has helped improved financial viability of NWSC'.

\section{Approach to Performance Monitoring and Benchmarking}

There is need to improve and monitor performance enhancement towards achievement of benchmarks. This follows the general saying that "if you cannot watch it, forget it!" A credible monitoring and evaluation mechanism puts pressure on the operating utility to improve performance. The utility must be aware that its performance is being watched and something will be done on its level of performance. An evaluation mechanism that does not take full cognisance of the regulator-regulated interface is worthless. The utility must know that a "bite" will strike in case of non-compliance and a "carrot" will appear in cases of target achievement. The evaluation criteria must be announced before hand and no "after-the-fact- 
adjustment" to the evaluation policy should be allowed. The NWSC monitoring and incentive framework significantly follows the following ten guidelines (in italics) identified by Sappington (1994) for designing incentive regulation plans:

- Use incentive regulation to better employ the firm's superior information.

- $\quad$ Prioritize regulatory goals and design incentive regulation to achieve stated goals.

- $\quad$ Link the firm's compensation to sensitive measures of its unobserved activities.

- Avoid basing the firm's compensation on performance measures with excessive variability.

- $\quad$ Limit the firm's financial responsibility for factors beyond its control.

- $\quad$ Adopt broad-based performance measures where possible, unless their variability is excessive.

- Choose exogenous performance benchmarks.

- Allow the firm to choose among regulatory options, while recognizing the interdependencies among the regulatory options that are offered to the firm.

- $\quad$ Promise only what can be delivered, and deliver whatever is promised.

- Plan for the rare, unforeseen event, but minimize after-the-fact adjustments to the announced regulatory policy.

More specifically, the following box outlines the practices/lessons learned in NWSC in respect to monitoring performance indicators for improved performance.

1. Purposive-based performance targets: The practice has been to set and emphasize performance targets in areas that specifically enhance financial viability and operating efficiency. The selected targets are also easy to measure without creating conflict between the regulator/monitor and the operators during the performance evaluation exercise.

2. Performance targets whose effects are easily informed by regular customer satisfaction surveys: Most targets in the contracts are such that the operator's efforts toward achieving them can be verified through a service effectiveness assessment conducted via regular customer perception surveys.

3. Carefully planned performance evaluation and feedback to operators: The practice has been to monitor process performance indicators as proxies for ultimate output performance indicators. This monitoring is carried out at relatively shorter time intervals, giving timely feedback to operators to pre-empt inadequate performance. An example of a proxy process performance indicator is proportion of water leaks responded to out of the number reported. This measure is monitored on a monthly basis as a proxy for the quarterly unaccounted-for water target.

4. Incentive mechanisms that rationally apportion operating risks to both parties: The practice has been to strike an acceptable balance between what the operators, through experience, view as highly effort-intensive targets and those requiring minimum effort to achieve. The guiding criteria for the balance are: (a) fairness and 
acceptability, (b) a net added financial benefit to NWSC after an incentive has been earned and paid, (c) a simple incentive structure easily marketable to the operator's lower level staff who will implement the contracted business plans, (d) variability of incentives earnable must correlate well with variability in the operator's unobserved performance efforts.

5. Adequate provision in contracts for possibilities of an integrated monitoring system as part of the employer's obligations (regulator is part and parcel of the employer): The emphasis has been to structure the monitoring/regulatory framework so as to achieve knowledge synergies from differently skilled staff. The monitoring structure has, throughout the contracts, been built around the core performance areas relating to technical operations, finance and accounts, and administration and customer care.

6. Tailor-made performance incentives as performance drivers: Performance incentives incorporated in all contracts were arrived at after prior detailed inquiries to find out what motivates staff most. The cash amount of the incentives is dependent on the number of optimum staff in each town, and was/is generally dictated by the town's internal cash generation capacity. It also depends on the performance expectations and ambitions for each town. The orientation was not how much the key operator staff "pocket" but how much all staff who actively participates in operations get. The sharing rules were/are very explicitly defined in the contracts before they are signed.

\section{Balancing Input and Output Orientations to Performance Monitoring}

\subsection{The Rationale}

According to Mugisha et al (2004), 'incentive-based performance monitoring is, by and large, associated with a philosophy of non-interference. The intent is to give the operator maximum incentive for innovation and to reduce oversight costs by the performance monitor/regulator. This approach can be very effective if it is not misinterpreted or misunderstood. The bottom-line objective of the non-interference policy is to enable the operating utility managers (agents) to use their informational superiority to enhance efficiency gains. When the operator lacks knowledge of new technologies or management techniques (because of the small scale of operations or through lack of experience), non-interference might lead to weaker performance than if the regulator/monitor (the principal) collaborated with the operator in a meaningful way. Although the monitor may lack knowledge about local demand conditions and resources, he or she may have access to other types of information that local operators lack'.

The implementation of the IDAMCs in NWSC culminated into a number of challenges similar to those alluded to by Mugisha et al (ibid.). As it is always said, programme design and commissioning it is one part of the story...monitoring or regulating it is another part. The advent of IDAMCs, per se, was therefore not a universal remedy. It entailed a significant number of supplements. NWSC management had to look at how to strengthen the monitoring apparatus so as to ensure optimal realization of objectives. At the time of introducing the IDAMCs, the corporation had a Department responsible for performance monitoring. However, the functionality of the monitoring activity needed further 
strengthening through wider managerial participation and effective human resource utilization at Head Office. The monitoring and evaluation activity in NWSC was heavily output oriented focusing on evaluation of target achievement and logistical requirements from Areas. There was no commensurate recourse on checking the authenticity of reports and accuracy of other performance figures reported. The monitoring activity was heavily coupled with evaluation of reported performance outputs and giving feedback.

Furthermore, the monitoring system lacked sufficient regard for inputs, processes and technologies necessary to deliver the requisite outputs and objectives of performance improvement programmes. As a result, the Head Office, as the principal, stood the risk of operating entities (Agents) not being able to deliver outputs as contained in the IDAMCs with no commensurate preventive approach. The real quagmire was what if the Agents did not deliver? Was it enough for Agents to lose incentives or get penalties or, at worst, have their contracts terminated? Wasn't the customer going to be the ultimate sufferer? The notion of partnering or working together with Agents, without necessarily interfering with their decision-making, was not well geared up. And yet, this approach was very crucial for systematic growth of operating entities. The managers at Head Office had good ideas of improving operations but there were no organized mechanism to enable them share these ideas to enhance what the Agents were doing. Whenever the managers wanted to share their ideas with the Agents, they would do it in a forceful way that would easily be construed as interference in Agents' conduct of business. This tended to cause significant suspicion and, clearly, this was a counterproductive approach to IDAMC implementation process. The principle of increased autonomy and empowerment was also not being exercised in a meaningful manner. In some occasions, the managers at Head Office wanted their good ideas operationalised, while the Agents wanted autonomy to decide what they wanted. Either side was right, according to the IDAMCs but there was a practical problem of how to actualize the relevant enabling IDAMC clauses.

By design, the IDAMCs put the asset ownership responsibility on Head Office and yet the operating entities (Agents) were in charge of operating and maintaining the assets. Although the IDAMCs provided sufficient safeguards for proper asset up keep, this was not enough in itself to safeguard against asset stripping due to poor maintenance practices. This was true especially given the fact that the Agents were under pressure to maximize incentives through cost containment activities. Indeed, during the private sector management periods in 
Kampala City, installations were not adequately maintained because of poor inspection methods by Head Office. The private contractors tended to direct fewer resources on infrastructure maintenance and this caused significant deterioration of equipment and premises in Kampala. The monitoring system only concentrated on targets compliance and did not adequately monitor the parent infrastructure (milking a cow without feeding it).

Apart from hardware infrastructure maintenance and upkeep, there were a number of problems relating to the orderliness and stature of managerial systems in Areas. It was predicted that the expected zeal to deliver IDAMC outputs to qualify for incentive awards could be coupled with shortfalls in respect to operational orderliness and managerial systems. For instance, some Head Office managers were saying that most Agents were not adequately following Procurement Laws. The premises ambiance had also gone down in some Areas and the general customer orientation had slumped. All these were process related issues that could easily be overlooked by Head Office for some time while it continued to pay handsome incentives on the basis of output performance. This was not sustainable in the long-run, leave alone distressing the hard-earned customer and public respect. Surely, something had to be done, at a strategic level, to ensure that the IDAMCs were meaningfully implemented. It did not make sense feasting on performance outputs from a "disorganized house". The cracks of the matter were about managerial and operational sustainability. Could the IDAMCs results be replicated on a temporal (sequential) basis?

The other, equally, apprehensive challenge was in respect to strengthening the predictability, transparency and objectivity of Head Office monitoring activities. It was perturbing that the Agents did not know what the Head Office monitors expected them to do and achieve in terms of inputs and technologies. The Agents were complaining that they, at times, received different monitoring teams, conflicting instructions and guidance. This was causing a lot of operational problems in terms of time wastage, monitoring ineptness and high costs. The Agents could not predict what the Head Office monitors wanted. Consequently, the monitoring activities were not carried out in a transparent and objective manner. This was indeed counterproductive for the IDAMCs. There was no sufficient resonance! The loser was not only the NWSC but the esteemed customer. Something had to be done. The corporation was confronted with a host of "how and what" questions, that needed solutions. The main solace, however, lay in the fact that the corporation had strong capacity in monitoring performance outputs and this was a good basis to strengthen its monitoring dimension relating 
to production processes and technologies. There was need to vigorously work on how to sustain results.

\subsection{Corrective Actions and Functionality Attributes}

In order to address the gaps identified above, a "checkers system" was designed and implemented, focussing on inputs and processes. Sets of monitoring checklists were generated by respective Heads of Departments at Head Office and negotiated with the operating entities to create common understanding of expected undertakings. The checklists were structured into general issues, relating to ambiance, customer care and corporate image. On the other hand, the checklists outlined issues relating to Departmental technical matters. The "checkers" system has been in place for about one year, since May 2005.

The functionality of the checkers system in NWSC has been a significant driver of the corporation's internal reform initiatives. The system has incorporated a comparative competition activity through which Areas have vigorously competed for checkers compliance. In this benchmarking activity, the emphasis is on cleanliness of premises, orderliness of offices, corporate image and systems operation and maintenance. There is no doubt that the checkers innovation has greatly strengthened the processes and technologies as well as the delivery of outputs. Areas have improved their efficacy to earn incentives in a more sustainable manner. In Kampala City for example the checkers system improved the new connections implementation processes, reducing the lead time and improving the technical quality of the work done in the field. In addition, compliance to financial regulations, procurement laws and other managerial procedures have greatly improved. In terms of technical capabilities, the operating entities have improved compliance to preventive maintenance programmes, operational procedures and safety nets. Last but not least, staff discipline, smartness and interfacing temperaments have greatly improved.

In general, the checkers system has verged positively on its objectives and has significantly addressed the gaps identified. The operating partners are happier because they know what they are expected to put in place. There is better time use because the checkers spend little time carrying out the checking activities. They do not waste the Agents' operational time, as was the case before. The follow-up on issues identified is also done in a coherent manner, ensuring that no issue is swept under "the carpet”. Many managers at Head Office get copies of the checkers findings and this helps to increase follow-up accountability. 
In addition, the monitoring costs have been rationalised, by building in robust cost containment safeguards. There is more value for money in this case.

However, the checking system has not been without challenges. There has been need for more dedicated individual checkers who are more objective and are opaque to capture by the operating entities. There are still some checkers who rank the operators close to maximum points when the actual situation on the ground has many gaps. The follow-up on issues identified also needs strengthening to ensure continuous improvements.

\section{Envisaged Performance Improvement Initiatives}

The implementation of internally delegated management contracts (IDAMCs) has been coupled with a number of efficiency gains. However, the first phase of the contracts expired in March, 2006 and arrangements have been made to transit into the next phase, with a number of improvements. The improvements on the model are in response to a series of periodic monitoring and evaluation activities of the programme. In line with the wider national water sector reform roadmap, the IDAMCs are being strengthened, for the next 2-3 years, incorporating more operating risks to operating Agents; more managerial autonomy in the areas of procurement, staff management, debt collection and static plant maintenance, among others. In addition, the strengthening measures include regionalisation into viable operating clusters (benefiting from increased economies of scale and scope); better contract design and incentive sharing plans; more challenging performance criteria and robust competition for managerial autonomy. Figure 1 below demonstrates the relationship between managerial autonomy and operating risk exposure (proportion of the operating partners' monthly pay that is pegged to a certain level of performance achievement). The design is such that the more autonomy you get the more operating risks you should be able to take on. Of course, risk taking is also leveraged by increased incentive awards. 


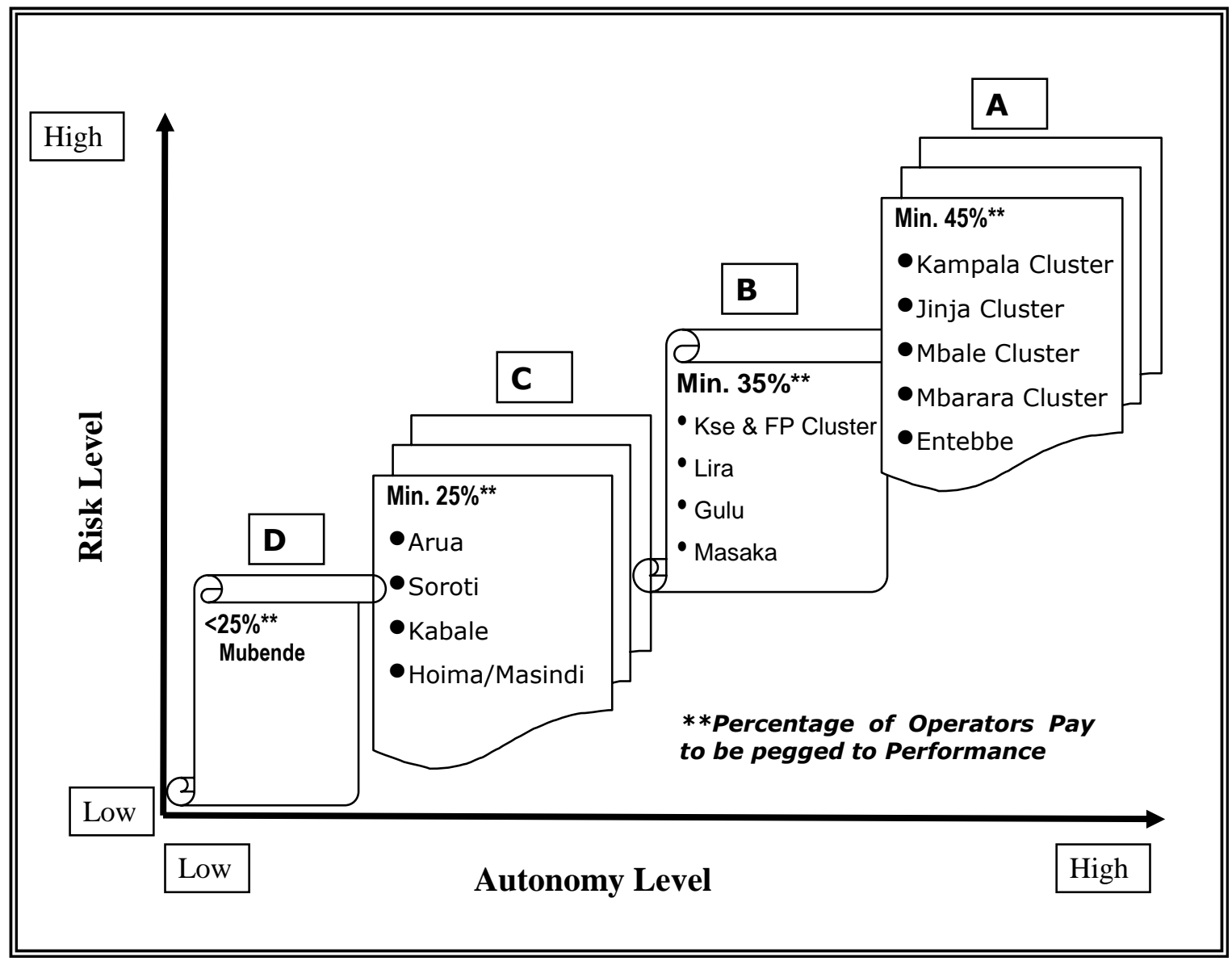

Figure 1: Relationship between Autonomy Levels and Risk Exposure

\section{The Role of Commercial and Customer Orientation ${ }^{3}$ on Utility Efficiency ${ }^{4}$ : A} Case of NWSC, Uganda

One of the success factors of performance improvement initiatives in NWSC was the shift balance between engineering and commercial/customer orientations. In order to demonstrate this fact, I present empirical evidence of the positive influence of commercial and customer care orientation on utility efficiency. I use stochastic production function

${ }^{3}$ Commercial orientation in this study assumes the meaning similar to Cullivan et al (1988) definition of commercialisation that relates to the degree to which actions in an institution are driven by cost effectiveness and operating efficiency. The authors point out that institutional performance should be guided by the urge to become self-sufficient financially at an appropriate stage in growth and that the institution should strive to establish a reputation as a financially well run business in the eyes of the financial and outside community. On the other hand, our understanding of customer orientation is similar to Kordupleski et al (1993) disposition that satisfying customers is essential to success: thus an effective organisation must listen to its customers and serve them effectively. Their conclusion is that 'if management can improve the internal measures, and if a statistical link exists between the internal process measures and quality as perceived by the customer, then a predictable improvement should also take place in customer perceived (true) quality'.

${ }^{4}$ This is the ratio of actual (observed) output relative to maximum output, given a set of production inputs. 
analysis methods to analyze the effects of commercial/customer care orientation on utility efficiency over a period of 9 years (1995-2004). Common performance parameters typical of an evolving water utility in a low income country are used. I investigate the main proposition, which states that "after a long spell of heavy engineering orientation ${ }^{5}$ in a water utility, a shift into significant commercial/customer orientation is positively associated with reduction in technical inefficiencies".

\subsection{Analytical Framework: Efficiency Estimation Methods}

\section{a) Efficiency Measurement}

According to Chen (2004), the traditional approach to performance evaluation and benchmarking in the water industry has been single-measure gap analysis. This involves use of separate efficiency indicators such as unaccounted for water, number of staff per 1000 connections and expenditure as a percentage of revenues generated. Chen posits that these measures are not substitutes for efficiency frontiers, which recognise the complex nature of interactions between inputs and outputs. There has, therefore, been a shift to the use of either data envelope analysis (DEA) or stochastic frontier analysis (SFA) methods for estimating efficiency of production. The measure of technical efficiency was introduced by Farrell (1957), deriving from the 1951 work of Debreu and Koopmans (both cited in Farrell, 1957) to avoid problems associated with traditional average productivity measures (ratios). Farrell proposed that efficiency could be determined relative to a best performance frontier derived from a representative peer group. According to Estache and Kouassi (2002), a firm is regarded as technically efficient if it is operating on the best practice production frontier in the industry. The degree of technical efficiency is given by the ratio of the minimal input required to the actual input use, given the input mix by the firm.

DEA involves the use of linear programming, whereas SFA involves the use of econometric methods. According to Coelli et al. (1998), some advantages of SFA models over DEA models include their capacity to account for noise and the potential for conventional tests of hypotheses (e.g., appropriateness of the model and the absence of technical inefficiency effects). However, SFA models have the following disadvantages, which DEA methods do not have: there is need to specify a distributional form for the inefficiency term

\footnotetext{
${ }^{5}$ This orientation involves predominant emphasis on engineering operations in an organisation at the expense of commercial/customer care operations.
} 
and to specify a functional form for the production function (or cost function, etc.), and it is more difficult to accommodate multiple outputs.

This study uses an SFA model to estimate firm efficiencies in view of inherent data inaccuracies associated with inadequate data management traditions in low-income countries. Under SFA modelling, we can consider different forms of functions: the production, cost or profit function. The cost and profit functions under SFA require the behavioural assumptions of cost minimisation and profit maximisation. The production function does not require any of these behavioural assumptions. This study utilises the production function because the cost and profit data for each utility cannot be accurately assessed due to long history of a centralised and combined accounting system in NWSC (up to 1999).

According to Estache and Kouassi (2002), there are several other reasons why a production function is preferred over a least-cost function in utility performance research in Africa: (1) in most African countries, the production cost structure is either not known or the degree of uncertainty surrounding the cost structures is relatively high; (2) in most classical papers, capital and length of the network are two key variables but they are highly correlated (multi-collinearity issue), which means that only one of these variables must be used, not the two of them; (3) in the specific context of Africa, the number of connections is a very important variable since the average family size is 7-9 (a free rider issue); (4) a production function has a variable $\mathrm{t}$ (time) which captures technological impact in the African water industry.

\section{b) Stochastic Frontier Production Models}

The general stochastic frontier production function, for a set of panel data, has the form of:

$$
\text { In } y_{i t}=f\left(x_{i t}, t ; \beta\right)+\xi_{\text {it }} \text {, }
$$

where $y_{i t}$ denotes output, $x_{i t}$ is a matrix of inputs, $t$ represents time $(t=1,2, \ldots . . T), \beta s$ are unknown technological parameters to be estimated and $f$ is some appropriate functional form.

The error term is $\xi_{\mathrm{it}}=\mathrm{v}_{\mathrm{it}}-\mathrm{u}_{\mathrm{it}}$, where $\mathrm{v}_{\mathrm{it}} \mathrm{s}$ are assumed to be independent and identically distributed (i.i.d.) random errors which have normal distribution with mean zero and unknown 
variance, $\sigma_{v}$ and $u_{i t} s$ are non-negative random variables which are associated with technical inefficiency in production of firms in the industry involved.

The ratio of the observed output for the $i^{\text {th }}$ firm, relative to the potential output, defined by the frontier function, given the input vector, $x_{i t}$ is used to define the technical efficiency of the $i^{\text {th }}$ firm:

$T E_{i t}=\frac{y_{i t}}{\exp \left(x_{i t} \beta\right)}=\frac{\exp \left(x_{i t} \beta-u_{i t}\right)}{\exp \left(x_{i t} \beta\right)}=\exp \left(-u_{i t}\right)$.

According to Coelli et al. (1998), the stochastic frontier model in (1) above is not without problems. The main criticism is that there is generally no a priori justification for the selection of any particular distributional form of the $\mathrm{u}_{\mathrm{it}} \mathrm{s}$. The specifications of more general distributional forms, such as the truncated-normal and the two parameter gamma, have partially alleviated this problem, but the resulting efficiency measures may still be sensitive to distributional assumptions. Huang and Ho-Chuan (2004) point out that the gamma-model exhibits richer and more flexible parameterization of the inefficiency distribution but its application is limited because of its complexity in evaluating the log likelihood function.

Stochastic frontier production functions can assume either a trans-logarithmic stochastic frontier production function or a Cobb-Douglas functional form. A translogarithmic stochastic frontier model incorporates estimation of coefficients $(\beta \mathrm{s})$ for second order input quantities. This function offers a more flexible form, although inclusion of the second order and cross-terms leaves the model with very few degrees of freedom. A simple Cobb-Douglas functional form is the most commonly applied specification in water benchmarking studies (e.g., Estache and Rossi, 2002) but it is better to start with a more comprehensive translog specification and carry out suitable tests to check whether the CobbDouglas provides a better representation of a given set of data. The parameters of the stochastic frontier production function, defined by Equation 1, can be estimated by using either the maximum likelihood (ML) method or the corrected ordinary least squares (COLS) method (Richmond, 1974, cited in Coelli, et al., 1998). The COLS approach is not as computationally demanding as the ML method, but empirical studies (Coeli, 1995) have found that the ML estimator is significantly better than the COLS estimator when the contribution of the technical inefficiency effects in the total variance term is large. The contribution of technical inefficiency to the total variance term is significantly apparent in 
NWSC water utilities, given their history of managerial inefficiencies (Mugisha et al., 2004a). The ML estimator is therefore a better estimator of the unknown parameters of Equation 1, given the NWSC panel data used in this study.

\section{c) Panel Data Models and their Attributes}

If a number of firms are observed over a number of time periods, then the data obtained are known as panelled data, which may be balanced or unbalanced depending on whether the number of firms in each time period is equal or different, respectively. If data is available for only one time period, it is called cross-sectional data. Panel data has several advantages over cross-sectional data: (1) it amplifies the sample size and alleviates the data shortage problem and (2) it allows for simultaneous estimation of both technical change and technical efficiency change over time. In African water utilities, which have recently been under constant pressure (mostly from development partners) to improve efficiency, the assumption that technical inefficiency effects are time-invariant is more difficult to justify as $\mathrm{T}$ in Equation 1 becomes larger. This study, therefore, employs a time-varying inefficiency modelling approach.

\section{d) Investigating Effects on Firm Technical Inefficiencies}

A number of researchers (e.g., Pitt and Lee, 1981, cited in Coelli et al., 1998) have investigated factors affecting technical inefficiencies among firms in an industry by carrying out regression analysis of predicted inefficiency effects, obtained from frontier modelling, on a set of firm-specific factors such as firm size, type of management option, etc., in a secondstage analysis. According to Coelli et al 1998, this approach faces one potential pitfall. In the first stage it is assumed that the inefficiency effects (in Equation 1) are independent and identically distributed (i.i.d.) in order to use the frontier analysis methods. In the second stage (regression analysis), this i.i.d. assumption is violated unless all the coefficients of the factors are simultaneously equal to zero. Consequently, researchers such as Kumbhakar et al. (1991) and Battese and Coelli (1995) noted this inconsistency and specified enhanced stochastic frontier models in which inefficiency effects were incorporated as explicit functions of some firm-specific factors, and all unknown scalar parameters were estimated in a single-stage ML procedure. According to Battese and Coelli (1995), for the $i^{\text {th }}$ firm in the $t^{\text {th }}$ period, technical inefficiency effect, $\mathrm{u}_{\mathrm{it}}$, is obtained by truncation of the $\mathrm{N}\left(\mu_{\mathrm{it}}, \sigma^{2}\right)$ distribution i.e.:

$\mathrm{u}_{\mathrm{it}}$ : truncation of $\mathrm{N}\left(\mu_{\mathrm{it}}, \sigma^{2}\right)$ 
$\mu_{i t}=z_{i t} \delta$,

where $z_{i t}$ is a $(1 \mathrm{xM})$ vector of observable explanatory variables whose values are fixed constants, and $\delta$ is an (Mx1) vector of unknown scalar parameters to be estimated. With the specification in Equation (4), it is assumed that an appropriate parametric representation of technical change, e.g., non-neutral technical change in a translog frontier, is specified in the array of $\mathrm{x}$-input variables for the frontier. The ML estimation of this model specification is programmed within the FRONTIER version 4.2 program (Coelli, 1996) and is called "Model 2 " or the "technical efficiency (TE) effects model". This study investigates the effects of commercial/customer orientation on firm-specific inefficiencies, and hence Model 2 of FRONTIER 4.1 computer program is used.

\subsection{Empirical Application}

\section{a) Model Data and Specification}

The study utilises panel data for NWSC utilities (except Kampala) for the period 19962004. Because of the different periods under which some utilities have been progressively added on to NWSC operational jurisdiction, the data is unbalanced. Accordingly, the panel ranges from eight utilities in 1996 to fourteen in 2004, as shown in Table 1

Table 1: Utilities under NWSC since 1995/96

\begin{tabular}{|l|l|}
\hline PERIOD & $\begin{array}{l}\text { NUMBER OF UTILITIES (EXCL. } \\
\text { KAMPALA })\end{array}$ \\
\hline $1995-96$ & 8 \\
\hline $1996-2002$ & 10 \\
\hline $2002-2004$ & 14 \\
\hline
\end{tabular}

Kampala water utility is left out because it is significantly different from the other utilities. Its operations account for about 65 percent of NWSC operations (scale advantages), and it has been under private sector management since 1997, which makes it unsuitable for a study of utilities that have long been under public-public incentive contracts. The sample data include annually assessed measures of water billed (WB) in cubic metres /day as the output; the inputs are water delivered $(\mathrm{P})$ in cubic metres/day, number of connections $(\mathrm{C})$, water network length $(\mathrm{N})$ in kilometres and number of staff $(\mathrm{S})$. This input-output production technology was chosen because NWSC has all along been emphasising financial sustainability as the main objective. Because the government does not give NWSC subsidies 
to support its day-to-day operations, improving revenues has been the main pre-occupation of NWSC improvement programmes in the period considered. The structure of the input-output variables chosen also relates well with what has commonly been used in most empirical applications in similar settings e.g. Estache and Kouassi (2002). Consequently, the summary statistics are presented in Table 2. The sample consists of unbalanced panelled data of 14 cross-sections, 9 time periods and 100 observations.

Table 2: Summary Statistics

\begin{tabular}{|c|c|c|c|c|c|}
\hline Variable & $\begin{array}{l}\text { Sample } \\
\text { Mean }\end{array}$ & $\begin{array}{l}\text { Sample } \\
\text { Standard } \\
\text { Deviation }\end{array}$ & Minimum & Maximum & Type of Variable \\
\hline Water Billed ( $\mathrm{m}^{3} /$ day) & 2,141 & 1,818 & 150 & 9,341 & Output \\
\hline Water Delivered ( $\mathrm{m}^{3} /$ day) & 3,418 & 2,870 & 250 & 11,163 & \multirow[t]{4}{*}{ Input } \\
\hline Staff (No.) & 64 & 37 & 17 & 147 & \\
\hline Connections (No.) & 2,410 & 1,591 & 350 & 8,545 & \\
\hline Network Length $(\mathrm{km})$ & 80 & 42 & 22 & 236 & \\
\hline $\begin{array}{l}\text { Market Size (Target } \\
\text { Population) }\end{array}$ & 63,707 & 27,946 & 22,353 & 144,178 & Environmental \\
\hline
\end{tabular}

For the stochastic frontier approach, we initially specify a translog stochastic frontier production function, based on Equation 1 as follows:

$$
\begin{aligned}
\ln \left(\mathrm{WB}_{\mathrm{it}}\right)= & \beta_{0}+\beta_{\mathrm{P}} \ln \left(\mathrm{P}_{\mathrm{it}}\right)+\beta_{\mathrm{S}} \ln \left(\mathrm{S}_{\mathrm{it}}\right)+\beta_{\mathrm{C}} \ln \left(\mathrm{C}_{\mathrm{it}}\right)+\beta_{\mathrm{N}} \ln \left(\mathrm{N}_{\mathrm{it}}\right)+\beta_{\mathrm{PP}}\left(\ln \left(\mathrm{P}_{\mathrm{it}}\right)\right)^{2}+\beta \mathrm{cc}\left(\ln \left(\mathrm{C}_{\mathrm{it}}\right)\right)^{2}+ \\
& \beta_{\mathrm{NN}}\left(\ln \left(\mathrm{N}_{\mathrm{it}}\right)\right)^{2}+\beta_{\mathrm{SS}}\left(\ln \left(\mathrm{S}_{\mathrm{it}}\right)\right)^{2}+2\left\{\beta_{\mathrm{PS}} \ln \left(\mathrm{P}_{\mathrm{it}}\right) \ln \left(\mathrm{S}_{\mathrm{it}}\right)+\beta_{\mathrm{PC}} \ln \left(\mathrm{P}_{\mathrm{it}}\right) \ln \left(\mathrm{C}_{\mathrm{it}}\right)+\right. \\
& \left.\beta_{\mathrm{PN}} \ln \left(\mathrm{P}_{\mathrm{it}}\right) \ln \left(\mathrm{N}_{\mathrm{it}}\right)+\beta_{\mathrm{SC}} \ln \left(\mathrm{S}_{\mathrm{it}}\right) \ln \left(\mathrm{C}_{\mathrm{it}}\right)+\beta_{\mathrm{SN}} \ln \left(\mathrm{S}_{\mathrm{it}}\right) \ln \left(\mathrm{N}_{\mathrm{it}}\right)+\beta_{\mathrm{CN}} \ln \left(\mathrm{C}_{\mathrm{it}}\right) \ln \left(\mathrm{N}_{\mathrm{it}}\right)\right\}+\beta_{\mathrm{t}} \mathrm{t}+ \\
& \beta_{\mathrm{tt}} \mathrm{t}^{2}+\mathrm{v}_{\mathrm{it}}-\mathrm{u}_{\mathrm{it}} ; \\
& \mathrm{i}=1,2, \ldots \ldots, \mathrm{N} \text { (number of utilities); } \mathrm{t}=1,2, \ldots \ldots \ldots, 9
\end{aligned}
$$

where $\mathrm{WB}_{\mathrm{it}}=$ water billed (in cubic.m/day) by the $\mathrm{i}^{\mathrm{th}}$ utility in the $\mathrm{t}^{\text {th }}$ year; $\mathrm{P}_{\mathrm{it}}=$ water delivered (in cubic.m/day); $\mathrm{C}_{\mathrm{it}}=$ connections (in numbers); $\mathrm{N}_{\mathrm{it}}=$ water network length (in $\mathrm{Km}) ; \mathrm{t}=$ time trend; "In" refers to natural logarithm and $\beta_{\text {is }}$ are unknown parameters to be estimated; $\mathrm{v}_{\mathrm{it}} \mathrm{s}$ are random errors as defined in Equation 1. The $\mathrm{u}_{\mathrm{it}} \mathrm{s}$ are non-negative random variables associated with firm technical inefficiencies and are assumed to be i.i.d. such that the distribution of $u_{i t}$ is obtained by truncation at zero of the normal distribution with mean $\mu_{\text {it }}$ and variance $\sigma_{\mathrm{u}}^{2}$, where:

$\mu_{\mathrm{it}}=\delta_{0}+\delta_{\mathrm{CCO}}\left(\mathrm{Z}_{\mathrm{CCOit}}\right)+\delta_{\mathrm{M}}\left(\mathrm{Z}_{\mathrm{Mit}}\right)$ 
and where Zs are "efficiency" explanatory variables - in this case, the environmental variables, namely, market size and commercial/customer orientation (CCO). The $\delta$ s are unknown scalar quantities $\left(\delta_{\mathrm{CCO}}\right.$ and $\left.\delta_{\mathrm{M}}\right)$ to be estimated. A negative value of $\delta \mathrm{j}$ would mean that the corresponding environmental variable has a positive impact on the reduction of firm technical inefficiencies (see Equation 2). The inclusion of market size (target population), M, in the production function is important, particularly in the context of African water utilities where service coverage is still low (50-80 percent in NWSC utilities). It is an excellent proxy for service area. According to Coelli et al. (1999, cited in Estache et al., 2002), measuring net efficiency relative to environmental factors is an important issue, as it allows one to predict how companies would be ranked if they were operating in equivalent environments. $Z_{\mathrm{CCO}}$, in this study is taken as a dummy variable; taking on a value of " 1 " for the years 1999-2004; when there was a significant shift from engineering to strong commercial/customer orientation. $\mathrm{Z}_{\mathrm{CCO}}$ takes on a value of " 0 " for the years 1996-1998 when the orientation in NWSC was heavily engineering.

\section{b) Model Analysis Results}

The maximum-likelihood (ML) estimates of the translog function in Equation 5 above are obtained by using the computer program FRONTIER version 4.1 developed by Coelli (1996). Because the production function (Equation 5) involves estimation of technical inefficiency effects, the technical efficiency (TE) model - "Model 2" - is selected. We take advantage of the great flexibility of the translog stochastic frontier model to test the following null hypotheses: (1) that the utilities are fully efficient, i.e. there are no technical inefficiency effects $\left(\mathrm{H}_{0}: \gamma=0\right)$; (2) that the Cobb-Douglas production specification is an adequate representation of the data, given the specifications of the translog function $\left(\mathrm{H}_{0}: \beta_{\mathrm{PP}}=\beta_{\mathrm{SS}}=\right.$

$\beta_{\mathrm{CC}}=\beta_{\mathrm{NN}}=\beta_{\mathrm{PS}}=\beta_{\mathrm{PC}}=\beta_{\mathrm{PN}}=\beta_{\mathrm{SC}}=\beta_{\mathrm{SN}}=\beta_{\mathrm{CN}}=0$ ); (3) that the environmental variables are not significant $\left(\mathrm{H}_{0}: \delta_{\mathrm{CCO}}=\delta_{\mathrm{M}}=0\right)$. The alternative models, estimated as a result of imposing the above restrictions, are tested using Likelihood Ratio (LR) tests. This test is based on the $\log$ likelihood function as follows:

$$
\mathrm{LR}=-2\left(\mathrm{~L}_{\mathrm{R}}-\mathrm{L}_{\mathrm{U}}\right)
$$

where $\mathrm{L}_{\mathrm{R}}$ is the $\log$ likelihood of the restricted model and $\mathrm{L}_{\mathrm{U}}$ is the $\log$ likelihood of the unrestricted model. Asymptotically, the LR statistic has a chi-square distribution with degrees of freedom equal to the number of restrictions involved. According to Lee (1993), where the 
null hypothesis includes the restriction $\gamma=0$ (a point on the boundary of the parameter space), the likelihood ratio statistics will have asymptotic distribution equal to a mixture of chi-square distribution $\frac{1}{2} \chi_{0}^{2}+\frac{1}{2} \chi_{1}^{2}$. The hypothesis test results are shown in Table 3 .

Table 3: Null Hypothesis Tests

\begin{tabular}{|l|l|l|l|}
\hline NULL HYPOTHESIS & $\begin{array}{l}\text { LOG } \\
\text { LIKELIHOOD }\end{array}$ & $\chi_{0.99}^{2}$ VALUE & $\begin{array}{l}\text { TEST } \\
\text { STATISTIC } \\
(\text { LR })\end{array}$ \\
\hline Given Model (from equation 13) & 66.15 & & \\
\hline $\begin{array}{l}\mathrm{H}_{0}: \beta_{\mathrm{PP}}=\beta_{\mathrm{SS}}=\beta_{\mathrm{CC}}=\beta_{\mathrm{NN}}=\beta_{\mathrm{PS}}=\beta_{\mathrm{PC}}=\beta_{\mathrm{PN}}=\beta_{\mathrm{SC}}=\beta_{\mathrm{SN}} \\
=\beta_{\mathrm{CN}}=0\end{array}$ & 47.62 & 23.21 & 37.06 \\
\hline $\mathrm{H}_{0}: \gamma=0$ & 53.14 & $14.33^{*}$ & 26.02 \\
\hline $\mathrm{H}_{0}: \delta_{\mathrm{CCO}}=\delta_{\mathrm{M}}=0$ & 57.59 & 11.34 & 17.12 \\
\hline
\end{tabular}

* Critical value of a mixture of chi-square $1 / 2 \chi_{0}{ }^{2}+{ }^{1} / 2 \chi_{1}{ }^{2}$ distribution obtained from Table I of Kodde and Palm (1986).

From the results of Table 3, we reject all three null hypotheses and conclude that (1) there are technical inefficiency effects, (2) the environmental variables are significant and (3) the Cobb-Douglas production function is not an adequate representation of the data set, given the specifications of the translog function in Equation 5. Consequently, the FRONTIER 4.1 program maximum likelihood estimates based on the translog stochastic production function in Equations 5 and 6, are shown Table 4:

Table 4: Maximum Likelihood Estimates

\begin{tabular}{|c|c|c|c|}
\hline & coefficient & standard-error & t-ratio \\
\hline beta 0 & 3.903 & 0.994 & 3.928 \\
\hline beta 1 (water del., $P$ ) & 1.503 & 0.305 & 4.924 \\
\hline beta 2 (staff, $S$ ) & 2.643 & 0.757 & 3.491 \\
\hline beta 3 (connections, $C$ ) & -2.609 & 0.825 & -3.162 \\
\hline beta 4 (network length, $N$ ) & -0.578 & 0.289 & -1.200 \\
\hline beta 5 $\left(P^{2}\right)^{6}$ & -0.148 & 0.227 & -0.650 \\
\hline beta 6 $\left(S^{2}\right)$ & 0.194 & 0.187 & 1.037 \\
\hline
\end{tabular}

${ }^{6}$ We note that beta 1 (on P) has a positive coefficient but beta 5 (on P-squared) has a negative one, implying that the "net" elasticity depends on the amount of water delivered. Taking partial derivatives of equation 5 with respect to $\mathrm{P}$ using the coefficients in table 4 , we obtain $\delta \ln \left(\mathrm{WB}_{\mathrm{it}}\right) / \delta \ln \left(\mathrm{P}_{\mathrm{it}}\right)=1.503-$ $0.296 \ln \left(\mathrm{P}_{\mathrm{it}}\right)+0.694 \ln \left(\mathrm{S}_{\mathrm{it}}\right)+0.400 \ln \left(\mathrm{C}_{\mathrm{it}}\right)-0.508 \ln \left(\mathrm{N}_{\mathrm{it}}\right)$. The latter clearly shows that if ln $(\mathrm{Pit})>$ $\left[1.503+0.694 \ln \left(\mathrm{S}_{\mathrm{it}}\right)+0.400 \ln \left(\mathrm{C}_{\mathrm{it}}\right)-0.508 \ln \left(\mathrm{N}_{\mathrm{it}}\right)\right] / 0.296$, we get a negative effect. On the other hand, $\delta \ln \left(\mathrm{WB}_{\mathrm{it}}\right) / \delta \ln \left(\mathrm{C}_{\mathrm{it}}\right)=-2.609+0.232 \ln \left(\mathrm{C}_{\mathrm{it}}\right)+0.400 \ln \left(\mathrm{P}_{\mathrm{it}}\right)-1.720 \ln \left(\mathrm{S}_{\mathrm{it}}\right)+1.234 \ln \left(\mathrm{N}_{\mathrm{it}}\right)$ implying that if $\ln \left(\mathrm{C}_{\mathrm{it}}\right)>\left[2.609-0.400 \ln \left(\mathrm{P}_{\mathrm{it}}\right)+1.720 \ln \left(\mathrm{S}_{\mathrm{it}}\right)-1.234 \ln \left(\mathrm{N}_{\mathrm{it}}\right)\right] / 0.232$, we get positive effects. 


\begin{tabular}{|c|c|c|c|}
\hline beta $7\left(C^{2}\right)$ & 0.116 & 0.419 & 0.276 \\
\hline beta $8\left(N^{2}\right)$ & -0.217 & 0.608 & -0.357 \\
\hline beta $9\left(P^{*} S\right)$ & 0.347 & 0.137 & 2.529 \\
\hline beta10 $\left(P^{*} C\right)$ & 0.200 & 0.358 & 0.559 \\
\hline beta11 $\left(P^{*} N\right)$ & -0.254 & 0.255 & -0.996 \\
\hline beta12 $\left(S^{*} C\right)$ & -0.860 & 0.223 & -3.851 \\
\hline beta13 $\left(S^{*} N\right)$ & -0.097 & 0.088 & -1.095 \\
\hline beta14 $\left(C^{*} N\right)$ & 0.617 & 0.528 & 1.168 \\
\hline beta15 $(t)$ & 0.102 & 0.028 & 3.369 \\
\hline beta16 $\left(t^{2}\right)$ & -0.007 & 0.003 & -2.408 \\
\hline delta 0 & 4.603 & 1.223 & 3.763 \\
\hline delta 1 $(M)$ & -0.412 & 0.109 & -3.780 \\
\hline delta 2 $(C C O)$ & -0.123 & 0.128 & -0.957 \\
\hline sigma-squared & 0.063 & 0.015 & 4.118 \\
\hline gamma & 1.000 & 0.000 & 969494 \\
\hline
\end{tabular}

Log likelihood function $=66.15 ;$ LR test of the one-sided error $=26.02$, with number of restrictions $=4$

[Note that this statistic has a mixed chi-square distribution]; mean efficiency $=81.27 \%$.

Table 4 shows that the production elasticities (measured by betas) are positive with respect to water delivered elasticity (beta 1) and staff (beta 2). The water delivered elasticity is not surprising given that the billing efficiency (water billed: water produced) has been improving from about 60 percent in 1998 to about 80 percent in 2004. The staff elasticity is also not surprising given that the staff productivity (number of staff/1,000 connections) has significantly improved since 1998 through deliberate staff rationalisation activities. The elasticities with respect to connections and network length are surprisingly negative. The negative connection elasticity is likely attributable to a relatively large proportion of disconnected accounts (about 15-20\%) that do not directly contribute to water billed (output production). This tends to create an excess input situation. The negative network length elasticity is probably attributable to the organisation's social mission objective, which means that water mains extensions are not necessary driven by efficiency considerations, in reality rendering this sunken investment initially redundant.

The beta value for the technical change factor $(t)$ suggests that there has been continuous positive annual technological progress (frontier shift) over the period of study. In NWSC utilities, this is expected, given that there has been continuous improvement of the management information systems, e.g., increased computerisation. This has made it possible 
to continuously develop the capacity to produce maximum output given the same vector of input quantities. The two environmental variables market size (M) and commercial/customer orientation (CCO) have negative coefficients. According to equation (2) and (4) this result suggests that the two variables are positively associated with reduction in technical inefficiencies. We note from table 4, however, that the M-coefficient is significant while the $\mathrm{CCO}-$ coefficient is insignificant.

\section{Conclusion}

From this paper two main conclusions come out. First, the performance improvement programmes in NWSC have demonstrated that public organizations can deliver adequate performance if well managed. Management and staff of the organization need to embrace change as a constant factor and this approach has helped to ensure continuous innovation and hence improved performance in NWSC. There is need to implement effective commercial and customer care management to derive optimal value from water infrastructure investments. In this respect, what has happened in NWSC is not unique to Uganda but can be replicated in other developing countries of comparable operating environments. The second conclusion relates to the empirical analysis presented. The evidence confirms the study proposition that after a long spell of heavy engineering orientation in a water utility, a shift from significant commercial/customer to engineering orientation is positively associated with reduction in technical inefficiencies. The result contributes to the body of knowledge in respect to water infrastructure management policy in low income countries. It is a good primer for managers seeking to carry out performance-led reforms aimed at enhancing financial and commercial sustainability. It is a good lesson for policy makers who think that only engineers can lead water-based companies.

\section{References}

Battese, G.E., and Tim Coelli (1995), "A Model for Technical Inefficiency Effects in a Stochastic Frontier Production Function for Panel Data," Empirical Econometrics, 20, 325-332.

Chen Lin (2004), “Quality-Incorporate Benchmarking in Public Utilities: An Application to the Peru Water Sector,” Working Paper, University of Florida, USA.

Coelli, Tim, D.S. Prasada Rao and George E. Battese (1998), “An Introduction to Efficiency and Productivity Analysis," Kluwer Academic Publishers 
Coelli, T.J. (1996), “A Guide to FRONTIER Version 4.1: A Computer Program for Frontier Production Function Estimation”, CEPA Working Paper 96/08, Department of Econometrics, University of New England, Armidale.

Coelli, Tim (1995), "Estimators and Hypothesis Tests for a Stochastic Frontier Function: A Monte Carlo Analysis," Journal of Productivity Analysis 6: 247-68.

Cullivan D, Tippett B, Edwards B Daniel, Rosensweg F \& McCaffery J (1988), "Guidelines for institutional assessment of water and waste water institutions", WASH Activity No 146, Washington, DC.

Estache, Antonio, and Eugene Kouassi (2002), "Sector Organisation, Governance and the Inefficiency of African Water Utilities," Research Paper, World Bank Institute, Washington, D.C.

Estache, Antonio, Martin A. Rossi and Christian A. Ruzzier (2002), "The Case for International Coordination: Evidence from the Measurement of Efficiency in South America," World Bank Policy Research Working Paper 2907, Washington, D.C.

Farrell, M.J. (1957), “The Measurement of Production Efficiency," Journal of Royal Statistical Society, Series A, 120: 253-81

Huang (River) and Ho-Chuan (2004), "Estimation of Technical Inefficiencies with Heterogeneous Technology," Journal of Productivity Analysis 21: 277-96

Kodde, David A., and Palm C. Franz (1986), "Wald Criteria for Jointly Testing Equality and Inequality Restrictions," Econometrica 54 (5), 1243-48

Kordupleski Raymond E., Roland T. Rust \& Anthony J. Zahorik (1993), "Why Improving Quality does not Improve Quality (Or Whatever Happened to Marketing?)”, pp82-95, California Management Review, Volume 35, Number 3, University of California.

Kumbhakar, S.C., S. Ghosh and J.T. McGuckin (1991), “A Generalised Production Frontier Approach for Estimating Determinants of Inefficiency in U.S. Dairy Farms," Journal of Business and Economic Statistics 9: 279-86.

Lee, L. (1993), “Asymptotic Distribution of the Maximum Likelihood Estimator for Stochastic Frontier Function Model with a Singular Information Matrix," Economic Theory 9: 413-30 
Mugisha, Silver, Sanford V. Berg, and Heather Skilling (2004), "Practical Lessons for Performance Monitoring in Low-Income Countries: The Case of National Water and Sewerage Corporation, Uganda," Water 21, October: 54-56.

Muhairwe, T. William (2006), "Turning around the NWSC-Uganda: Improving Efficiency, Increasing Access and Creating Financial Sustainability" Presented for the $4^{\text {th }}$ World Water Forum, Unpublished NWSC Working Document on www.nwsc@nwsc.co.ug

Sappington, David E. M. (1994), "Designing Incentive Regulation," Review of Industrial Organization, 9, 245-272. 